\title{
Planejamento Estratégico
}

\author{
Adailson da Silva Duarte \\ Universidade Severino Sombra, Centro de Letras, Ciências \\ Sociais Aplicadas e Humanas, Curso de Administração \\ ddt-duarte@hotmail.com \\ Claudio Rodrigues Amaral \\ Universidade Severino Sombra, Centro de Letras, Ciências \\ Sociais Aplicadas e Humanas, Curso de Administração \\ c.c.amaral@hotmail.com \\ Eber José Vasconcelos Costa \\ Universidade Severino Sombra, Centro de Letras, Ciências \\ Sociais Aplicadas e Humanas, Curso de Administração, \\ ebervasconcellos@yahoo.com.br
}

\begin{abstract}
Resumo: Ao ser elaborado este trabalho, levaram-se em conta os pensamentos do planejamento estratégico no paradigma pós-fordista, bem como a sua não utilidade no fordismo. Assim, serão expostas, juntamente, as relações de trabalho nos dois paradigmas, indicando como a presença ou ausência do planejamento estratégico transforma o modelo de trabalho dentro de uma organização. Para tal, foi feito comparações entre autores que falam sobre o assunto, buscandose a interpretação mais adequada com o objetivo de esclarecer para os futuros estudos, colaborando de forma sistemática e objetiva um novo enunciado, pois, o que se estuda num momento sofre transformações no momento seguinte, e o que se quer, é buscar uma atualização de dados que possam referendar o estudo ora iniciado, apresentando o momento fordista e o momento pós-fordista, o que ele representou num momento e o que representa no momento atual, e, com isto, será possível estabelecer orientações cabiveis para um melhor enunciado.
\end{abstract}

Palavras-Chaves: Fordismo. Trabalho. Planejamento. Estudos.

\section{Strategic Planning}

\begin{abstract}
When preparing this work, we took into account the thoughts of strategic planning in post-Fordist paradigm, and its usefulness in non-Fordism. So it will be exposed along the working relationships in the two paradigms, contextualizing the presence or absence of strategic planning becomes the model of working within an organization, for that was made comparisons between authors who speak on the subject, seeking to more appropriate interpretation in order to clarify for future studies, collaborating in a systematic and objective a new statement, because what we study is transformed in a moment the next moment, and what we want, is to seek an update of data that may thus initiated
\end{abstract}


referendum on the study showing the time Fordist and post-Fordist moment, it stood for a moment and what it stands at present, and this will be possible to establish reasonable guidelines for a better statement.

Keywords: Fordism. Working. Planning. Studies.

\section{Introdução}

Este trabalho tem por finalidade esclarecer os pontos paradigmáticos nas relações fordistas e pós-fordistas, estabelecendo pontos em comum entre eles assim como as suas discordâncias. Utilizaremos o processo metodológico de comparação sistemática, buscando-se o fenomenológico hermenêutico, como nos orienta Fazenda (1991).

A pesquisa foi elaborada levando-se em conta os pensamentos do planejamento estratégico no paradigma pós-fordista, bem como a sua confrontação no fordismo. Consequentemente, serão identificadas as características dos dois paradigmas, contextualizando como as relações de trabalho influenciam a utilização do planejamento estratégico pela organização. Com a necessidade da adequação das organizações à flexibilidade, surgiu a priorização do uso de uma nova ferramenta administrativa chamada de planejamento estratégico. Por meio deste se manifestam novas formas de controle. O objetivo do trabalho é estudar as novas formas de controle compatíveis com a introdução do planejamento estratégico nas organizações.

Com este pensamento, o que se pretende com a busca exploratória dos argumentos é oferecer um viés interpretativo, que venha a colaborar com futuras pesquisas, pois um trabalho de verificação de conteúdo tem por finalidade averiguar, pesquisando os pontos positivos e negativos, para, posteriormente, oferecer sugestões que contribuam com a pesquisa científica, daí a nossa interpretação ter o caráter qualitativo.

\section{Referencial Teórico}

Será que o funcionário de hoje está realmente livre daquela forma rígida e opressora de controle e submissão vista no mundo fordista? Com o intuito de responder a essa questão nosso trabalho define de forma sucinta o planejamento estratégico, confronta-o com o paradigma fordista e explica sua adaptabilidade ao pós-fordismo, usando como contextualização A corrosão do caráter, de Richard Sennett. Esse trabalho expõe principalmente as formas de controle do planejamento estratégico no modelo pós-fordista e como essas formas de controle mudam as relações de trabalho expostas por Sennett.

\section{Planejamento Estratégico}

As organizações, para alcançar seus objetivos, têm a necessidade das seguintes funções administrativas: Planejamento, Organização, Direção e Controle. Para alcançar tais objetivos e metas, são estabelecidas missões, valores, análise de ambiente externo e interno. Nesse processo administrativo, o planejamento estratégico, sobretudo se tratando do controle, é essencial, pois atinge todos os pontos da estrutura organizacional e faz um 
diagnóstico de pontos fortes e fracos da organização. As formas de controle do planejamento estratégico transformam as estruturas organizacionais, alterando consequentemente, as relações de trabalho.

O Planejamento estratégico surge no período pós-fordista, momento esse em que as empresas buscavam sempre uma forma de se adequar às necessidades do mercado, prática exercida pela alta administração, mas que envolve a todos dentro da estrutura organizacional, pois está focada para a melhoria na produtividade da organização. Observa-se que as preocupações, no que diz respeito às organizações, são comuns tanto aos dirigentes, diretores e gerentes quanto aos operários, pois somente com o comprometimento de todos dentro da organização é que se pode conseguir algo para a melhora do chamado clima organizacional. Líderes das diversas organizações tendem a confundir orçamento com planejamento. As instituições estatais são exemplos disso, nessas os orçamentos são quase em sua totalidade dirigidos para os custos da folha de pagamento.

O Planejamento Estratégico visa a difundir essa co-responsabilidade na empresa com os seus diretores, pois entendendo todo o processo e participando ativamente nas pequenas decisões o funcionário se sentirá muito mais motivado e comprometido com a organização. Para que se possa alcançar os objetivos previamente definidos pelos dirigentes da organização temos o CONTROLE que por sua vez pode ser executado por todos, inclusive pelos gerentes e diretores. Esses tem a incumbência de fazer a organização gerar resultados positivos, porém tais resultados não são apenas responsabilidades dos diretores, mas também do corpo operacional da organização. E no que remete ao corpo operacional, a autodisciplina será uma contribuição importante para manter o controle de todas as atividades operacionais.

Embora muitas vezes esta etapa não seja levada em consideração, as etapas do monitoramento e controle são essenciais, pois, segundo Maximiano (2006), o monitoramento "consiste em acompanhar e avaliar a execução da estratégia“. O monitoramento deve ser realizado com base nos mesmos indicadores utilizados na hora de se elaborar o planejamento estratégico. Esse acompanhamento e essa avaliação na execução da estratégia serão realizados por meio do monitoramento e controle, porém o planejamento estratégico tem uma forma diferente de estabelecer controle e monitoramento. No mundo pós-fordista, as formas de controle mudaram conforme a exigência imposta por esse novo paradigma. Muitas vezes, apenas na etapa de controle é que os administradores descobrem que as coisas não estão ocorrendo de acordo com o que foi planejado. A função do controle estratégico é assegurar que objetivos sejam atingidos.

O planejamento estratégico, sobretudo se tratando de suas novas formas de controle, é uma ferramenta que busca garantir a concretização de objetivos, e para assegurar tal, estrutura-se no controle estratégico e nessa busca a segurança necessária ao sucesso da organização. Maximiano (1987, p.286) reporta-se ao assunto da seguinte maneira:

"O controle do tipo estratégico tem por finalidade acompanhar o desempenho da organização no que diz respeito à realização de sua missão, e também acompanhar o comportamento dos fatores ambientais que a afetam, visando a produzir informações que permitam a tomada 
de decisões sobre os objetivos estratégicos planejados e os recursos envolvidos em sua perseguição".

O controle tático será importante no planejamento estratégico no sentido de que as várias áreas dentro de uma organização precisam ser avaliadas. E esse controle tático, permitirá a concretização das decisões tomadas a nível estratégico. A avaliação de atividades dos vários setores de uma forma mais focada irá permitir o sucesso dos objetivos e metas estipulados. Afinal, objetivos e metas estão entre os principais fatores que guiam uma organização que utiliza o planejamento estratégico. (Tenório, 2006, p.99).

O controle operacional, junto com os outros níveis de controle garantirá a realização dos planos estratégicos contidos no planejamento estratégico. As tarefas serão supervisionadas com o intuito de garantir que as informações do planejamento estratégico sejam seguidas. Os instrumentos utilizados serão; orçamentos, cronogramas, regras e regulamentos (planos relacionados com os comportamentos). A forma de poder que o planejamento estratégico estabelece nas organizações pode muito bem ser vista nas regras e regulamentos em que os funcionários são submetidos. Eo controle operacional, principalmente, ajudarána segurança das concretizações das informações ditadas pelo planejamento estratégico, os empregados serão submetidos a novas formas de controle, pormenorizadas do presente texto.

A ferramenta administrativa orientadora, ou seja, o planejamento estratégico é uma forma de pensar e agir realizada por meio de planos antecipados, guiado por objetivos a serem alcançados por meio da eficiente utilização dos recursos disponíveis com a finalidade de atingir metas na organização. Motta $(2007$, p.85) reporta-se ao assunto da seguinte maneira: "Essa visão valorizava o aperfeiçoamento de métodos racionais de ação administrativa para produzir maior eficiência e eficácia na antecipação de mudanças".

O pensamento em que o planejamento estratégico está pautado reflete em eficiência que deve ser passada por toda estrutura, inclusive nas relações de trabalho, por meio do convencimento de cada funcionário, para que haja um mesmo objetivo a ser alcançado por todos na organização. A flexibilidade e a adaptação ambiental vêm a ser integrantes e características fundamentais de uma sociedade moderna capitalista, e esses fatores vão dar um toque de necessidade à adoção de um planejamento estratégico nas organizações. Ao falar sobre o assunto, Motta (2007, p.85) faz a seguinte observação:

Consequência direta da aquisição da visão perspectiva sistêmica e contingencial em administração, o planejamento estratégico parte da premissa de um ambiente em constante mutação e turbulência, que exige um processo contínuo de formulação e avaliação de objetivos, baseado em fluxo de informações sistemáticas sobre as transações entre ambiente e organização, que determinam possíveis variações no senso de missão socioeconômica da empresa.

O mundo econômico turbulento em que as organizações estão inseridas no mundo pósfordista, irá tornar fundamental o uso do planejamento estratégico. A competitividade acirrada pelas mudanças, a obrigatoriedade para com o consumidor em quesitos de qualidade mesclada a consideração do ambiente externo interferindo nas relações de 
trabalho, por meio de um conceito incerto com o futuro profissional de cada funcionário e a forma como as relações de trabalho se estabelecem, como veremos posteriormente, será fruto de uma forma de ação gerencial flexível que usa como ferramenta o planejamento estratégico. O mundo deixa de ter a previsibilidade do fordismo, a padronização do pensamento tanto quanto dos produtos não atende ao mercado moderno. Flexibilidade de produção acaba atingindo a ação gerencial. A ação gerencial monológica já não comporta as mudanças. A hierarquia burocratizada é substituída por uma visão sistêmica dada pelo pós-fordismo. Nos tópicos que se seguem, iremos ver como o planejamento estratégico irá sustentar as ideias e contextos do pós-fordismo e os motivos do uso do planejamento estratégico não ser adequado ao fordismo.

\section{Uma Análise do Planejamento Estratégico e do Paradigma Fordista, Contextualizando-os com a Corrosão do Caráter, de Richard Sennett}

O Fordismo, implantado por Henry Ford, é um modelo de organização de produção e do trabalho. Surge no setor secundário da economia, em específico na indústria automobilística. As linhas de montagem, com seus métodos de produção em massa continuam a seguir as características tayloristas de racionalização e padronização. A questão hierárquica continua forte, evidenciando a divisão entre a concepção e execução, os funcionários são submetidos às técnicas repetitivas de produção de bens, sem possuírem o direito de opinar sobre elas (Tenório 2000, p.135/141).

As considerações do modelo fordista vão ajudar-nos na compreensão de que a forma de pensar clássica da administração científica, inserida no fordismo pela perpetuação da racionalização e padronização taylorista não estará em comum acordo com o planejamento estratégico. Diz-se que o planejamento estratégico por ser sistêmico atinge a todos os pontos da organização, contrariando a divisão rígida de concepção e execução. Os funcionários passam a ser mais participativos nos objetivos da empresa e a produção de bens não visa mais a simples padronização. Continua sim, a eficiência como parâmetro de seguimento. Mas a forma horizontal de dividir o poder vai ser fruto da diferenciação do mercado que exige uma nova forma de poder. Diferenciação de mercado irá resultar em flexibilização na produção e, também, na maneira como as relações de trabalho são estabelecidas. Tudo isso será visto no pós-fordismo, uma contrariedade ao fordismo.

O modelo econômico, tecnológico e organizacional fordista, pratica a ação gerencial monológica, que segundo Tenório (2000, p.151) "é uma combinação de competência técnica com atribuição hierárquica". O conhecimento técnico era o que ditava o centro de poder. Nessa relação, os engenheiros detentores do saber técnico obtinham o poder sobre os operários, plena separação entre os que pensam para os que executam. Portanto, o fato é que o fordismo com a padronização, enfoque interno, hierarquia burocratizada, visão a longo prazo previsível, não terá o planejamento estratégico como ferramenta administrativa.

Com a crise do fordismo acontecida por conta da gestão monológica que, por sua forma rígida de racionalização do trabalho não atendia as mudanças comportamentais, políticas e econômicas da modernidade, surge o pós-fordismo. O modelo pós-fordista, enquadrado na flexibilidade, na forte influência do ambiente externo, na forma sistêmica de pensar a organização, na visão de um futuro imprevisível. Todos esses motivos reforçam a não utilidade do planejamento estratégico no fordismo e reforçam sua importância no pós- 
fordismo que surge nesse contexto de novo mundo.

A hierarquia organizacional fordista é rígida, o planejamento é feito por poderosos detentores de conhecimento técnico, em um momento que o trabalho se fazia em função de um modelo de produção novo, a linha de montagem passa a ditar o ritmo das operações de trabalho. Os engenheiros pensam e planejam, enquanto os operários fazem o que lhes cabe fazer. Ordens sistemáticas, reflexo de uma gestão monológica, racionalizam o trabalho em tarefas bem especificadas por normas de excelência, os trabalhadores são reféns do tempo estabelecido pelas máquinas, que determinam a movimentação dentro da fábrica.

A produção em massa de bens padronizados e de baixos custos passa a ser uma realidade no fordismo, devido à economicidade da mão de obra e através da linha de montagem. Ford introduziu A norma fordista de salários: implanta salários relativamente elevados e crescentes, uma espécie de compensação aos esforços repetitivos e enfadonhos. Foi uma contribuição à melhoria de vida aos trabalhadores. Foi criada por Henry Ford a jornada de trabalho de 8 horas por dia, cinco dólares por dia, igualmente a bonificação e a participação pela produtividade da indústria. A linha de montagem ditava as regras do jogo e os trabalhadores eram meros participantes. Devido ao processo de trabalho repetitivo predominante, ocorria a alienação dos funcionários assim como um trabalho entediante. Era uma prestação de serviço do subordinado hierárquico bastante opressora, devido ao rígido controle de suas tarefas (Tenório, 2000, p.142/ 145).

Sennett (2009) ao narrar a vida de Rico contrastando com a do pai Enrico nos mostra os fatores da relação de trabalho, expressa ao longo do livro, como no capítulo 2, que aborda a rotina. Ela é perfeitamente compatível ao mundo fordista de trabalho. “(...) os empregos dos trabalhadores especialistas eram aqueles tipos de operações em miniaturas que exigiam pouco pensamento ou julgamento." (Sennett, 2009, p.44/45). Esse fragmento do texto de Sennett deixa clara as relações de trabalho na era fordista e ressalta as questões hierárquicas, racionais a que os trabalhadores eram submetidos.

"Na geração de Enrico, porém, a métrica de tempo já se tornara outra coisa que não um ato de repressão e dominação praticado pela administração em nome do crescimento da gigantesca organização industrial." (Sennett, 2009, p.48). Nesse fragmento do texto de Sennett, pode-se visualizar claramente a métrica de tempo em um planejamento rígido, girado em torno das máquinas e a questão entre a separação do planejamento para a operação prática dos pensamentos. São aspectos fortes no fordismo e em suas relações de trabalho. A ausência da ferramenta do planejamento estratégico, como visto nas relações de trabalho expressas por Sennett, num mundo fordista, é a diferença fundamental num olhar estrutural das organizações, elas são extremamente estruturais e não visualizam o ambiente externo, concorrência, elas são rígidas. O planejamento estratégico ,ao contrário do planejamento rígido do fordismo, significa uma visão de planos antecipados que levem em conta: o ambiente externo, a análise da concorrência e como superá-la, a estruturação organizacional sistêmica e a flexibilidade nas relações de trabalho. 


\section{O Planejamento Estratégico junto ao Paradígma Pós-Fordista e Como Isso Veio a Intervir nas Relações de Trabalho, Por Meio da Flexibilidade}

O planejamento estratégico é incorporado ao pós-fordismo, por meio da flexibilidade, utilizando-se da efemeridade e adaptação ambiental. Agora, é o mercado quem dita as regras, exige diferenciação bem como qualidade e quantidade. Em função do imprevisível ambiente em que se apresenta, há a necessidade de adaptação às mudanças constantes feitas através da flexibilidade. O planejamento estratégico com todos esses fatores adicionados ao modelo flexível de gestão obtém novas noções em visão organizacional. O pós-fordismo quebrou a rigidez extrema e opressora anteriormente vista no paradigma fordista, passa a pensar mais em flexibilidade, trazendo como consequência as mudanças nas relações de trabalho e as estruturas organizacionais tendem a ser mais horizontais. Os recursos humanos viram uma política inovadora, vinda para o aperfeiçoamento das relações do trabalho (Tenório, 2000, p.163).

Observa-se em detalhes essa estrutura inovadora que se denomina flexibilidade e como ela vem a interagir nas relações de trabalho em Senett (2009), cap. 3, flexibilidade. A flexibilidade faz com que o homem consiga se adaptar às mais diversas circunstâncias, tornando-o adaptável às mudanças constantes. As organizações visam, por meio da criação de instituições flexíveis, a destruição do sistema rotineiro, ou seja, a mudança por meio do paradigma pós-fordista e consequentemente por meio do planejamento estratégico. Sennett (2009, p.54), reporta-se ao assunto da seguinte maneira:

O sistema de poder que se esconde nas modernas formas de flexibilidade consiste em três elementos: reinvenção descontínua de instituições; especialização flexível de produção; e concentração de poder sem centralização. Os fatos que se encaixam em cada uma dessas categorias são conhecidos da maioria de nós, nenhum mistério; já avaliar a conseqüência deles, é mais difícil.

Contudo, dentro dessa busca por flexibilidade como é citado por Sennett acima, encontraram-se novas formas de poder e controle, tornando-se ilusória a idéia de livre ação e distanciando a mesma dos funcionários. Esse novo sistema de poder subdividiuse em três elementos: especialização flexível de produção; concentração do poder sem centralização e reinvenção descontínua de instituições (Tenório, 2000).

\subsection{Especialização Flexível}

Caracteriza-se pela alta tecnologia. Graças ao computador, a total informatização das máquinas é viável, permitindo a fácil reprogramação se necessário. As instituições passam a ter modernos meios de comunicações que põem a disposição das empresas dados globais imediatos. Essa forma de produção exige decisões em curto prazo dos pequenos grupos de trabalho, tais indivíduos são obrigados a dobrar-se perante a especialização, tornandose flexíveis, caso não queiram ser esmagados devido à força de tal mudança. "O sistema pós-fordista de produção se caracteriza, sobretudo pela sua flexibilidade” Tenório (2000, p.163). 
Como é possível observar a flexibilidade é uma característica do pós-fordismo, tornandose uma necessidade perante o competitivo mercado de trabalho, é necessário conhecimento ampliado de diversas áreas. Tal especialização flexível tenta por, cada vez mais em menor tempo, produtos mais variados no mercado.

\subsection{A Reinvenção de Instituições}

Vem acompanhada da utilização de programas de computadores, permitindo o total controle do andamento dos serviços na empresa, o que fornece acesso aos pontos defeituosos do sistema empresarial, ocasionando a retirada de tais pontos, sendo chamada de reengenharia, mais propriamente a redução de empregos, sendo sua principal característica. O objetivo da re-engenharia e das organizações é produzir mais com menos, porém nem sempre isso acontece, já que se é observado na maioria das vezes um fracasso. Essa ideia pode ser reforçada por meio do seguinte fragmento: "[...] flexibilidade se manifesta de varias formas: em termos tecnológicos; na organização da produção e das estruturas institucionais [...]" Tenório (2000, p.163).

\subsection{A Concentração de Poder Sem Centralização}

Dá as pessoas em postos de trabalho mais inferiores o direito e controle sobre suas funções. Em geral, pressiona a produção acima da capacidade individual, as empresas dão a seus funcionários uma falsa liberdade de produção. Não se obtém a verdadeira espontaneidade, e sim apenas um novo modelo de controle. Essa idéia pode ser reforçada pelo seguinte fragmento: "Nas modernas organizações que praticam a concentração sem centralização, a dominação do alto é ao mesmo tempo forte e informe" (Sennett, 2009, p.65). Por meio da união dos três elementos do regime flexível na organização do tempo de um determinado local de trabalho, tem-se uma clara estrutura de como atuam. "As organizações flexíveis hoje estão fazendo experiências com vários horários do chamado Flexitempo.” (Sennett, 2009, p.66). Quando a empresa dá liberdade aos seus funcionários de entrada ou saída de sua organização a livre arbítrio, ou até mesmo que vá trabalhar em casa, se fala em Flexitempo, onde ocorre por parte dos funcionários o alto controle de seu tempo de trabalho, sem deixar de cumprir o trabalho estabelecido, isso gera uma liberdade pessoal ilusória, ou seja, o funcionário pensa que tem o controle referente as suas tarefas, porem a empresa, o controla muito mais do que antes. "Os trabalhadores, assim, trocam uma forma de submissão ao poder - cara a cara — por outra, eletrônica". (Sennett, 2009, p.68). Pode-se observar no fragmento acima que Flexitempo, nada mais é do que uma forma de incentivar o individualismo deixando de lado o trabalho em equipe, e ainda assim deixando os funcionários muito mais submissos às empresas do que antes. 


\section{Conclusão}

Ao ser abordado, o planejamento estratégico incluído em sua constatação de uso ao pósfordismo e não utilidade no fordismo, viram-se as diferenças de relações de trabalho entre as duas concepções de modelos de gestão e como isso interfere nas próprias relações de trabalho. Bem como se observa no livro "A corrosão do caráter" de Richard Sennett, onde se abordam por meio de histórias de vida de Enrico e Rico, os fatores do fordismo (geração de Enrico) e pós-fordismo (geração de Rico). Fatores que só vão reforçar a ideia da utilidade do planejamento estratégico no pós-fordismo e da não utilidade no fordismo, através de citações desse livro também vimos aspectos do paradigma fordista e pósfordista constatando as ideias em um mundo moderno e contrastando com um passado visto como recente. Pode ser reforçada a importância do planejamento estratégico no mundo capitalista moderno e pós-fordista, porém é interessante dizer que as formas de planejamento fordistas têm sua importância em alguns contextos de maior segurança nas empresas. Terem maior controle sobre a organização. Apesar de a flexibilidade do pós-fordismo, como relata Sennett, englobar um novo sistema de poder e controle. $\mathrm{O}$ que se deve fazer é saber dosar da melhor forma possível o controle do fordismo com a flexibilidade do pós-fordismo. 


\section{Referências}

Fazenda, Ivani. Interdisciplinaridade: história, teoria e prática. Ática e Metodologia da Pesquisa Educacional. 7. ed. São Paulo, Cortez, 1991.

Maximiano, Amaru. Teoria Geral da Administração, Editora Atlas, Edição Compacta , 2005.

Motta, Paulo Roberto. Gestão contemporânea: A ciência e a arte de ser dirigente, Editora

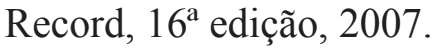

Sennet, Richard. A corrosão do caráter. Editora Record, 14ª edição, 2009.

Tenório, Fernando Guilherme. Flexibilização Organizacional. Mito ou Realidade? Editora Fundação Getúlio Vargas,2000

Tzu, Sun. A arte da guerra, Editora Record, 33 ${ }^{\mathrm{a}}$ edição, 2004. 